eCommons@AKU

January 2017

\title{
Bowled over by cricket: impact of tape-ball injuries on the eyes
}

Salman Naveed Sadiq

Aga Khan University

Azam Ali

Aga Khan University, azam.ali@aku.edu

Bushra Usmani

Aga Khan University, bushra.usmani@aku.edu

Khabir Ahmed

Aga Khan University, khabir.ahmed@aku.edu

Follow this and additional works at: https://ecommons.aku.edu/pakistan_fhs_mc_surg_surg

Part of the Ophthalmology Commons, and the Surgery Commons

\section{Recommended Citation}

Sadiq, S., Ali, A., Usmani, B., Ahmed, K. (2017). Bowled over by cricket: impact of tape-ball injuries on the eyes. Asia Pac J Ophthalmol (Phila)., 6(1), 50-53.

Available at: https://ecommons.aku.edu/pakistan_fhs_mc_surg_surg/528 


\title{
Bowled Over by Cricket: Impact of Tape-Ball Injuries on the Eyes
}

\author{
Salman Naveed Sadiq, Azam Ali, Bushra Usmani, and Khabir Ahmad
}

\begin{abstract}
Purpose: The aim of this study was to describe the type and severity of tape-ball cricket-related eye injuries seen at a tertiary care hospital.

Design: A descriptive case series.

Methods: This study included all cases of tape-ball cricket-related eye injuries presenting to the Section of Ophthalmology, Aga Khan University Hospital, Karachi, from January 2014 to January 2015.

Results: A total of 20 patients with tape-ball cricket-related eye injuries were treated during this period. The right eye was involved in most $(14 / 20)$ of the cases. The commonest presenting symptoms included reduced/blurred vision, ocular pain, redness, and floaters. Sixty percent $(12 / 20)$ of the affected eyes had a best corrected visual acuity of less than 20/200 at presentation, with the retina being the most commonly involved ocular structure. All patients reported that they were not wearing protective eyewear at the time of trauma. Despite standard management, half of the eyes had severe or total vision loss at the last follow-up (minimum, 3 months), mainly due to retinal damage.
\end{abstract}

Conclusions: Our study calls for the compulsory use of protective eyewear by cricket players and for countrywide surveillance data on the true burden of this "unnoticed" preventable cause of unilateral eye injuries and associated vision loss.

Key Words: eye injuries, tape ball, cricket, blindness, preventable injury, blunt trauma, protective eyewear

(Asia-Pac J Ophthalmol 2017;1:50-53)

$\mathrm{T}$ ape-ball cricket is a very popular sport in South Asian countries, including Pakistan, India, Sri Lanka, and Bangladesh. Because of the limited number of playgrounds and a lack of adequate regulations in these countries, the game is increasingly being played on streets and sidewalks. A tape ball is a tennis ball wrapped in electrical tape to give it the proper weight and speed. ${ }^{1}$ It is less dangerous to use than a conventional cricket ball, which is made of cork and covered with leather. The conventional ball used in professional cricket is hard, weighs 155.9 to $163.0 \mathrm{~g}$, and requires protective gear to play with.

Sports trauma remains a significant cause of ocular morbidity worldwide, and most of these injuries can be prevented. According to the National Eye Institute, sports with the highest rate

From the Section of Ophthalmology, Department of Surgery, Aga Khan University, Karachi, Pakistan.

Received for publication August 17, 2015; accepted February 23, 2016

The authors have no funding or conflicts of interest to declare.

Reprints: Salman Naveed Sadiq, Section of Ophthalmology, Department of Surgery, Aga Khan University, Stadium Rd, PO Box 3500, Karachi 74800, Pakistan. E-mail: salman_716@hotmail.com.

Copyright (C) 2016 by Asia Pacific Academy of Ophthalmology

ISSN: 2162-0989

DOI: $10.1097 /$ APO.0000000000000202 of eye injuries in the United States include baseball and basketball, followed by ice hockey, racquet sports, fencing, lacrosse, paintball, and boxing. In South Asia, millions of people play tape-ball cricket. However, there has been no published analysis of the spectrum of eye injuries it causes.

The aims of this report are to describe the type and severity of tape-ball cricket-related eye injuries and highlight the importance of protective headgear in this form of cricket.

\section{MATERIALS AND METHODS}

This was a descriptive case series involving individuals who presented to the Section of Ophthalmology, Aga Khan University Hospital, Karachi, Pakistan, with a recent history of tape-ball eye injuries between January 2014 and January 2015. The study was approved by the ethics review committee of Aga Khan University, Karachi (3412-Sur-ERC-14). Patients with a history of ocular trauma and those who underwent any surgical management before presenting to us were excluded. Data were collected from medical records using a pretested pro forma. Data collected included the complete case history, demographic details, best corrected visual acuity (BCVA), anterior and posterior segment findings, and intraocular pressure. Vision impairment and blindness were defined according to World Health Organization (International Classification of Diseases, 10th Revision) grading.

Patients received standard treatment and were followed up for at least 3 months. Final corrected VA was recorded at the last follow-up. Fifteen patients $(75.0 \%)$ required surgical intervention. The main surgery performed was retinal detachment repair $(\mathrm{n}=7)$ followed by intravitreal anti-vascular endothelial growth factor injections $(\mathrm{n}=3)$. Argon laser photocoagulation was used to treat retinal breaks $(n=2)$. Other procedures included primary repair of corneoscleral laceration and cataract extraction. Two patients did not show up for the surgery.

Data of additional investigations, including B-scan ultrasonography, fundus angiography, and optical coherence tomography (Heidelberg Engineering Spectralis), were reviewed where necessary to confirm the clinical diagnosis.

All data were entered and analyzed using SPSS software version 19.0 for Windows. Frequencies and percentages were calculated for categorical variables such as sex. The median was computed for numerical variables such as age and intraocular pressure. Tables and charts were used to present the results.

\section{RESULTS}

Twenty patients (20 injured eyes) were included in the study (Table 1). The median age of the patients was 20.5 years (range, 11.0-78.0 years). All of them were men except an 11-year-old girl who was a bystander accidentally hit by the ball. 


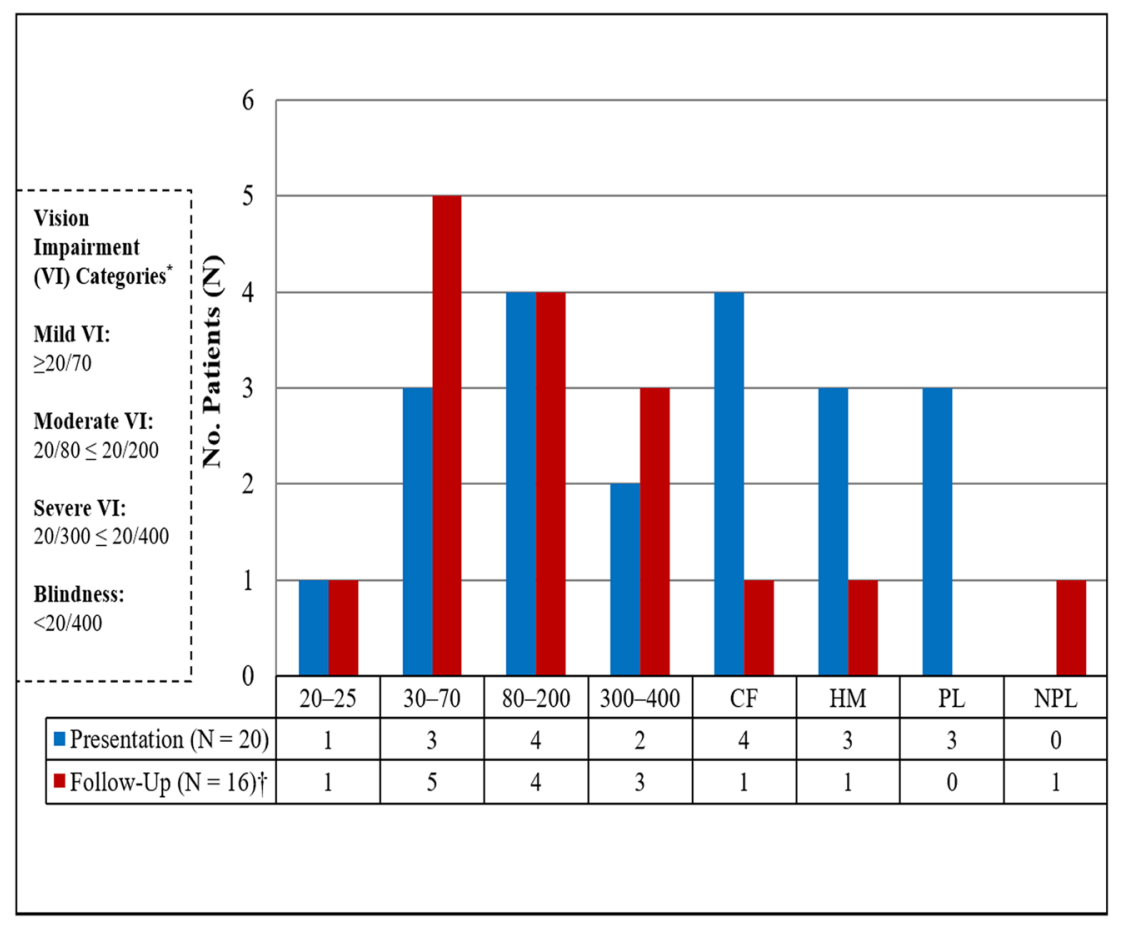

FIGURE 1. Snellen BCVA of the affected eyes at presentation and follow-up. *Categories of vision impairment according to World Health Organization 2015 (International Classification of Diseases, 10th Revision). †Four patients were lost to follow-up.

The right eye was involved in 14 patients $(70.0 \%)$. Blurring of vision was the most common symptom and was experienced by almost all patients with variable severity (Fig. 1). Less common symptoms included ocular pain, redness, and floaters. The median intraocular pressure at presentation was $11.5 \mathrm{~mm} \mathrm{Hg}$ (range, 4.0-50.0 mm Hg). Severe vision impairment (BCVA < 20/200) was seen in 12 patients $(60.0 \%)$ at presentation. Despite standard treatment, 6 patients $(37.5 \%)$ continued to have severe vision impairment (in at least 3 months of follow-up). Four patients $(20.0 \%)$ were lost to follow-up.

Traumatic involvement of almost every ocular tissue was seen (Table 2). The cornea was affected in $5(25.0 \%)$ of the patients. In 8 patients $(40.0 \%)$, the iris was affected. The crystalline lens and vitreous were each involved in 4 patients $(20.0 \%)$. The retina was by far themost commonly involved ocular structure, affecting 15 $(75.0 \%)$ of the patients. Furthermore, 9 patients $(45.0 \%)$ experienced rhegmatogenous retinal detachment, of which most $(n=7)$ had complete detachment involving the macula. Traumatic involvement of the choroid (Fig. 2) and optic nerve was also observed in 4 $(20.0 \%)$ and $2(10.0 \%)$ patients, respectively. None of the patients were wearing any ocular protection at the time of injury.

The reasons for severely impaired final vision included retinal detachment with advanced PVR $(n=3)$, persistent choroidal

\begin{tabular}{lc}
\hline TABLE 1. Demographic Characteristics of Patients \\
\hline Median (range) age, y & $20.5(11.0-78.0)$ \\
Sex & 19 \\
$\quad$ Male & 1 \\
$\quad$ Female & \\
Eye involved & 14 \\
$\quad$ Right & 6 \\
Left & \\
\hline
\end{tabular}

neovascularization after choroidal tear $(\mathrm{n}=2)$, and macular hole formation in 1 case. Six patients who underwent retinal surgery achieved favorable outcomes in anatomical reattachment of the

TABLE 2. Clinical Diagnosis at Presentation and Follow-Up*

\begin{tabular}{|c|c|c|c|}
\hline Ocular Tissue & Clinical Diagnosis & $\mathbf{n}$ & $\%$ \\
\hline Lids & Bruising & 2 & 10.0 \\
\hline Conjunctiva & Subconjunctival hemorrhage & 2 & 10.0 \\
\hline \multirow[t]{3}{*}{ Cornea } & Edema & 1 & 5.0 \\
\hline & Corneal abrasion & 1 & 5.0 \\
\hline & Corneoscleral laceration & 1 & 5.0 \\
\hline \multirow[t]{2}{*}{ Anterior chamber } & Hyphema & 4 & 20.0 \\
\hline & Angle recession & 1 & 5.0 \\
\hline \multirow[t]{3}{*}{ Iris } & Iridodialysis & 1 & 5.0 \\
\hline & Traumatic mydriasis & 4 & 20.0 \\
\hline & Traumatic uveitis & 3 & 15.0 \\
\hline \multirow[t]{2}{*}{ Crystalline lens } & Cataract & 3 & 15.0 \\
\hline & Cataract subluxed & 1 & 5.0 \\
\hline Vitreous & Hemorrhage & 4 & 20.0 \\
\hline \multirow[t]{8}{*}{ Retina } & Complete detachment (rhegmatogenous) & 7 & 35.0 \\
\hline & Partial detachment (rhegmatogenous) & 2 & 10.0 \\
\hline & Retinal hemorrhage & 1 & 5.0 \\
\hline & Macular hole & 1 & 5.0 \\
\hline & Retinal tear(s) & 2 & 10.0 \\
\hline & Commotio retina & 1 & 5.0 \\
\hline & Retinal dialysis & 1 & 5.0 \\
\hline & Macular scar & 1 & 5.0 \\
\hline \multirow[t]{2}{*}{ Choroid } & Tears/rupture & 4 & 20.0 \\
\hline & Choroidal neovascularization* & 3 & 15.0 \\
\hline \multirow[t]{2}{*}{ Optic nerve } & Traumatic neuropathy & 1 & 5.0 \\
\hline & Glaucomatous cupping* & 1 & 5.0 \\
\hline
\end{tabular}


retina and improved vision (Table 3).

\section{DISCUSSION}

Ocular trauma due to sports-related injuries is considered to be a significant cause of vision morbidity. ${ }^{2,3}$ A nationwide survey in the United States revealed that sports-related ocular injuries accounted for more than 100,000 physician visits per year. ${ }^{4}$ Baseball accounted for the maximum number of injuries, followed by basketball and tennis. However, injuries due to cricket are uncommon in Western countries. This is not the case in South Asian countries where street cricket is common, resulting in severe ocular injuries. A study carried out in Pakistan reported ocular trauma while playing cricket in $27.7 \%$ of cases presenting to a tertiary hospital. ${ }^{5}$ Another study from India cited that $15.2 \%$ of all pediatric ocular trauma was due to a cricket ball. ${ }^{6}$ To the best of our knowledge, this is the first study describing the type and severity of injuries due to tape ball.

Ocular trauma that occurs because of a ball is mostly a closed globe injury. ${ }^{7}$ It occurs because of the high speed at which the ball is traveling, having a direct impact on the globe resulting in coup and countercoup injuries. By covering a tennis ball with electrical tape, the ball's weight and traction are increased, which in turn leads to greater bounce and speed. An unwrapped soft tennis ball is compressible and rebounds slowly, which distributes its kinetic energy upon impact. The relatively harder tape ball strikes the eyeball with much greater speed and force, deforming the eyeball more, and rebounds faster, thus transmitting its force at a higher rate. It has been proven experimentally in various animal models that the higher the momentum of impacting objects, the more severe and posterior the damage to the eyeball. ${ }^{8,9}$ This is consistent with our study results in which $18(90.0 \%)$ of 20 sustained a posterior segment injury.

All of our cases had some degree of vision loss in the affected eye at presentation. Despite management, half of them continued to have severe or total vision loss, mainly secondary to retinal problems. However, there may be a possible overrepresentation of severe cases, as our institution is a tertiary care hospital with vitreoretinal services. Nevertheless, 12 patients $(60.0 \%)$ had severe injuries as defined by BCVA less than 20/200, and almost the

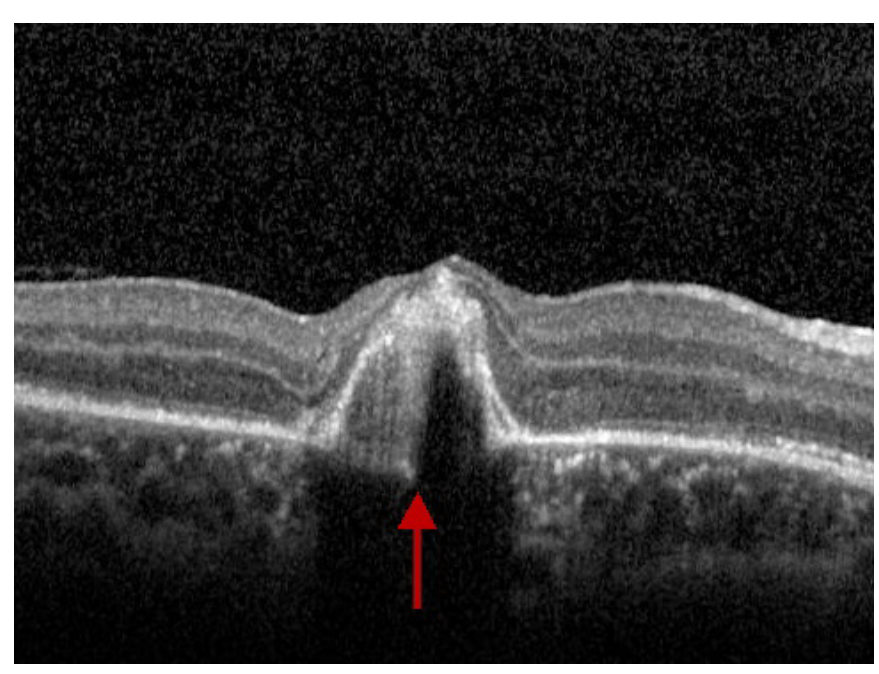

FIGURE 2. Right-eye optical coherence tomography image of an 11year-old patient demonstrating choroidal rupture leading to choroidal neovascularization formation.
TABLE 3. BCVA of Patients Who Underwent Retinal Detachment Surgery

\begin{tabular}{lcc}
\hline Case No. & Preoperative & Final (at Last Follow-up) \\
\hline 1 & HM & CF \\
2 & HM & $20 / 200$ \\
3 & HM & $20 / 80$ \\
4 & CF & HM \\
5 & CF & $20 / 200$ \\
6 & $20 / 400$ & $20 / 70$ \\
7 & $20 / 40$ & $20 / 30$ \\
\hline
\end{tabular}

same percentage required some sort of surgical intervention, mostly pars plana vitrectomy. Rhegmatogenous retinal detachment was seen in $9(45.0 \%)$ of our cases. A study by Qureshi et al achieved $75.0 \%$ anatomical success after surgery and favorable vision outcomes in most eyes with rhegmatogenous retinal detachment due to tennis ball injury. ${ }^{10}$ In our study, 6 patients $(37.5 \%)$ continued to have severe vision impairment at the final follow-up.

None of the patients were wearing any form of protective eyewear at the time of impact. One patient was wearing prescription spectacles that shattered, resulting in corneoscleral laceration. The street format of tape-ball cricket has not only caused potentially blinding injuries in players but has also affected bystanders, adding to its potential hazards. In our study, there were 3 patients who were bystanders, including an elderly 78-year-old man.

Most of these injuries could have been prevented through adequate eye protection. Studies have shown that proper eye protection reduces the risk of significant eye injuries by $90 \%{ }^{11,12}$ Therefore, proper protection is strongly recommended for batsmen and close fielders. As the use of head gear or helmets is practiced in professional cricket, it should similarly be encouraged at all levels of tape-ball cricket. The addition of a polycarbonate visor to the helmet enhances its safety and should also be considered. As most street cricketers purchase a cricket kit from sports shops, it should be mandatory to add a visor or helmet to the kit too. The use of glass spectacles and contact lenses while playing is highly contraindicated and should be discouraged. As reported in our study, along with others, ${ }^{13}$ contact lenses and glass spectacles pose a greater risk for ocular injury in case of a direct hit by the ball, resulting in the shattering of the glass or the contact lens, which injures the cornea. If spectacles are needed for refractive error correction, polycarbonate incorporated spectacles may be worn instead. ${ }^{7}$ Polycarbonate lenses are up to 8 times more impact resistant as compared with ordinary plastic or glass lenses. More recently, Trivex lenses are available, which offer greater protection and clearer vision than polycarbonate lenses. We recommend the use of these impact-resistant spectacles by all players, regardless of whether they have any refractive error.

Our study calls for the nationwide collection and analysis of data on the burden of tape-ball-related ocular injuries to determine the extent and thus the gravity of the situation. The media should create awareness regarding the importance of using protective eyewear. Playing in open grounds as opposed to streets should be encouraged, which will help reduce the injuries to bystanders and mere passers-by. Our results showed a high percentage of injuries involving the retina. Early detection and management of retinal breaks is essential to prevent retinal detachment. Hence, every patient of ball-related trauma must have a complete 
eye examination, including gonioscopy and examination of the peripheral retina, closely followed by the necessary treatment.

As Pakistan is a passionate cricketing nation, entirely eliminating tape balls from street cricket might not be possible. However, creating awareness regarding the risk of tape-ball ocular injuries and their prevention and prompt management may lead to better vision outcomes. As ophthalmologists, our major concern is preventing ocular trauma, reporting the rising incidence of tapeball-associated ocular injuries, and thus supporting the need to create awareness about the use of protective eyewear while playing tape-ball cricket. Twenty cases in 1 calendar year, with half of them having severe or total vision loss, warrant serious attention. Vision is far too precious to be allowed to be clean bowled by a tape ball.

\section{REFERENCES}

1. Samiuddin O. Pakistan's quicks get into the swing with tennis balls and electrical tape. The Guardian. 2006. Available at: http://gu.com/p/x8qve/sbl. Accessed on March 29, 2016.

2. Schein OD, Hibberd PL, Shingleton BJ, et al. The spectrum and burden of ocular injury. Ophthalmology. 1988;95:300-305.

3. Vinger PF. The incidence of eye injuries in sports. Int Ophthalmol Clin.
1981;21:21-46.

4. Napier SM, Baker RS, Sanford DG, et al. Eye injuries in athletics and recreation. Surv Ophthalmol. 1996;41:229-244.

5. Jan S, Khan S, Mohammad S. Hyphaema due to blunt trauma. J Coll Physicians Surg Pak. 2003;13:398-401.

6. Varghese LM, Savur S, Kulkarni U. Perils of street cricket: two uncommon cases of an eye for a ball. IOSR-JDMS. 2014;13:21-25.

7. Vinger PF. A practical guide for sports eye protection. Phys Sportsmed. 2000;28:49-69.

8. Delori F, Pomerantzeff O, Cox M. Deformation of the globe under highspeed impact: its relation to contusion injuries. Invest Ophthalmol Vis Sci. 1969;8:290-301.

9. Scott WRM, Lloyd WC, Benedict JV, et al. Ocular injuries due to projectile impacts. Ann Adv Automot Med. 2000;44:205-217.

10. Ch M, Khan WA. Traumatic retinal detachment due to tennis ball injury. Pak J Ophthalmol. 2007;23:151-154.

11. Strahlman E, Sommer A. The epidemiology of sports-related ocular trauma. Int Ophthalmol Clin. 1988;28:199-202.

12. Larrison WI, Hersh PS, Kunzweiler T, et al. Sports-related ocular trauma. Ophthalmology. 1990;97:1265-1269.

13. Capao Filipe JA, Rocha-Sousa A, Falcao-Reis F, et al. Modern sports eye injuries. Br J Ophthalmol. 2003;87:1336-1339. 